Suppressio Verl; Suggestio Falsi.

St. Louis, Mo., Oct. 9, 1897.

To the Editor:-In consideration of the above and the correspondence between Drs. Woodbridge and Upshur, I propose to give a brief sketch of $\mathrm{my}$ experience in typhoid fever in Missouri for over forty years.

In the fall of $1853 \mathrm{I}$ had charge of a family of seventeen persons, in age ranging from 1 to 20 years (Dr. C's. family). Called in consultation Dr. McD., a graduate of a Philadelphia medical college. We diagnosed typhoid fever in case one. The patient was about 20 years of age, of sanguine temperament and good health up to that time. Treatment began with a purgative dose of calomel, hot turpentine stupes over the bowels (right iliac region), aromatic sulph. acid as a drink, and Dover's powder at night. The diarrhea was kept within reasonable bounds by the two latter, increasing or lessening the amount according to circumstances. After his bowels were moved from the first purgative, we gave from $1 / 2$ to 2 grs. calomel every six hours. About the ninth day his tongue had cleaned and become moist. Tympanites and some pain subsided over bowels and he was convalescing rapidly, but contrary to orders be got up, dressed, and persisted in walking about his room. In the afternoon he was seized with a severe hemorrhage and within a period of about three hours died from perforation of the bowels (supposed). There is nothing out of the ordinary in this case. The unexpected termination, and the alarming con dition of the remaining sixteen called for the most deliberate and philosophic consideration. All had diarrhea, some were in bed, others preparing to go, and all without exception presented unmistakable evidences of type with the case above.

I proposed calomel in small doses as a curative and prophy. lactic. It was opposed on the ground of its constitutional effects. I referred the other two doctors to the old axiom, "A busus non tollit risum" and began by giving calomel $1 / 4$ to 2 grs. every four, six and eight hours, alternately with permanganate of pot. in similar doses. This treatment was given, with some variations, to the entire famlly of sixteen. All made good recoveries and in about three weeks were discharged.

In summing up the treatment which $I$ have invariably practiced, I wish to emphasize calomel and permanganate potass. (or if preferred as a matter of choice, bichlorid hydr.) in minute doses as a preventive, abortive or curative. Of course the many adjuncts, such a turpentine, arom. sulph. acid, etc. should and ought to be considered in many cases. The constitutional effects of the first named agent should always be sought for as speedily as possible and held there until the patient is beyond all danger of relapse.

In all cases where the stools are particularly offensive (and all are) the permanganate potass. should be continued until the fetor, etc., are corrected and this change is evidence of the destruction of the germs, poison, in other words, typhoid bacillus. In diet: Liquid food, buttermilk, sweet milk, raw eggs beat up with spts. frumenti, soups, etc.

My success in typhoid fever has been so completely satisfactory that I am not disposed to change this described treatment of it for any other.

In this article $I$ wish to place myself on record as endorsing the several articles in the Journal favorable to blood-letting (notably Dr. Todd, San Francisco) in pneumonia, puerpural con vulsions, certain conditions of the brain and stomach, etc.

$$
\text { J. M. Foreman, M.D. }
$$

\section{Wants the Discussion Continued.}

Milton, Del., Oct. 9, 1897.

To the Editor:-We have been watching the controversy which has been going on between Drs. Woodbridge and Upshur, yet it has not been interesting or edifying to your readers for we have been looking for them to eay something to confirm the abortive treatment of typhoid fever or vice versa. While we have not been able to indorse all that Dr. Woodbridge claims, yet we have reason to believe that there is some good in it and the antiseptics which he uses. We have ever believed in antisepticising of the alimentary canal in every disease, and purging out the accumulation of the ages, following this with some antiseptic remedy. There can never any harm occur from this course, but many, many times great good. But let the doctors comment and criticise each other as they may about the abortive treatment of Dr. W., however good or bad it may be, it will have a tendeney to revolutionize the treatment of typhoid fever and that of all others. The agitation of this by Dr. W., if it does nothing else, will cause the subject to be ventilated as perhaps no other has been since my debut into the profession. And whatever subject is gotten up for discussion in any direction will be beneficial and bring out and develop the truth. We say go on Doctors, but let us have less of your spleen and more of the cause and treatment of typhoid fever. J AMEs A. Hopkins, M.D.

\section{Hospital Interneships.}

Chicago, Sept. 30, 1897.

To the Editor:-I read with interest your editorial, "The Advantages of Hospital Interneship," in the last number of the Journal.

My opinion is that all agree in acknowledging the benefit of hospital training. Why do more students not secure to them. selves the advantages of such a training? Is it a want of appreciation on the part of the prospective physician? I think not.

The average student, yes, 95 per cent., are anxious to secure a place in some good hospital, in fact in any hospital. Place the blame where it belongs. The fact is that there are too few places of this kind to be filled. The case you cite illustrates my point very nicely. You say fourteen students came up for examination to fill twelve vacancies. Out of that fourteen twelve got hospital positions and two were disappointed. Had there been forty come up for the same examination twelve would have gotten places and twenty eight would have been counted out. That is one reason why more do not make the effort. Another will be found in the fact that those who anticipate taking the examination for hospital interneship devote their last year to "bucking" for examination, as they call it, to the exclusion of hospital and dispensary clinical work. Instruction under the tuition of their teachers is ignored entirely. What then happens to the unfortunate candidate? He finds himself, on graduation day, decidedly short in clinical experience, with but little prospect of getting more before entering active practice, unless he should be so fortunate as to have more money than many of them possess.

This can be remedied to some extent by shortening the period of interneship. If the term was made twelve months instead of eighteen months, just one-half as many more would receive the benefit of a hospital training. There are always more candidates than there are places.

The physicians who control our hospitals are responsible for this and to them should an appeal be made for móre internes and shorter service. Yours truly, A Subscriber.

\section{Death from Carbolic Acid.}

Weaverville, N. C., Sept. 23, 1897.

To the Editor:-I report this case as I have not been able to find one in which death took place so soon after taking so small a quantity of carbolic acid.

Mrs. Miles, aged 28, mother of two children, youngest 5 years old, was in the third week of typhoid fever, about the sixteenth day with temperature ranging from 100 degrees in the morning 